\title{
The Relationships between Leadership Behaviors Team Learning and Performance among the Virtual Teams
}

\author{
Talip Pınar ${ }^{1}$, Cemal Zehir ${ }^{2}$, Hakan Kitapçı1 ${ }^{1} \&$ Haluk Tanrıverdı ${ }^{3}$ \\ ${ }^{1}$ Faculty of Business Administration, Gebze Institute Of Technology, Turkey \\ ${ }^{2}$ Faculty of Economics and Administrative Sciences, Yıldı Technical University, Turkey \\ ${ }^{3}$ Faculty of Economics, Department of Tourism Management, Istanbul University, Turkey \\ Correspondence: Talip Pinar, Faculty of Business Administration, Gebze Institute Of Technology, Gebze, \\ Kocaeli, Turkey. E-mail: talippinar@gmail.com
}

Received: January 24, 2014

Accepted: March 12, 2014

Online Published: April 24, 2014

doi: 10.5539/ibr.v7n5p68

URL: http://dx.doi.org/10.5539/ibr.v7n5p68

\begin{abstract}
Teams are in the mid of a renaissance. Particularly in today's business environments, characterized by globalization, technological progress and intense competition, the virtual teams - as the work groups with members at different locations, using computer based communication and sharing inputs and other individual efforts through technology - are increasingly becoming prevalent. However there is still a gap in the literature concerning the performance and success of virtual teams. In this study, the interrelationships among leadership, team learning and team performance is theoretically and empirically investigated within the context of virtual teams. After a deep literature review a survey is conducted on 101 teams. The data is analyzed via PLS 3.0 statistical program. The path analyzes results show reveals the important role of leadership on team learning for virtual teams. Moreover the findings underline the vital role of team learning on team success and performance for virtual teams just like for the traditional teams.
\end{abstract}

Keywords: virtual teams, team learning, leadership

\section{Introduction}

Virtual teams are currently having a small place in terms of operation science although the rapid proliferation in the application (Badrinarayanan \& Arnett, 2008, Prasad \& Akhilesh, 2002; Ebrahim et al., 2009). Related with the subject, El-Tayeh et al. (2008) underlines the needs towards the theoretical and empirical studies which will be realized on the virtual teams and virtual team performances. When the differences between the time and place concepts are taken into account, it is been accepted that they have a close relationship with the performance of these teams. Thus, virtual teams have many advantages and a high level of flexibility but have also many problems about management and leadership (Bell \& Kozlowski, 2002). Many researches indicate that, leaders create a big difference in the team performance. While modelling the team work, the leader plays an important role in placing the rules of the team members in order that the team members are successful in the team work (Cascio \& Shurygailo, 2003; Yoo \& Alavi, 2004; Hertel et al., 2005). In the traditional management literature, despite many researches about leadership in teams, there are not many studies about leadership in virtual teams (Yoo \& Alavi, 2004; Hertel et al., 2005).

Another concept which can be related to the performance in the virtual team framework is team learning. At the team output point, team learning means the problem solving ability of a team. Team learning as a different concept of individual and organizational learning, defines the solution development of a team by proceeding step by step, and requires an appropriate leadership understanding and management —in the teams which are among the traditional borders in terms of time and place (Kayes, 2003).

Team learning has an important role on the success and performance by providing that the teams develop rapid and efficient solutions to complex and unexpected problems (Lyons \& Schneider, 2005). Especially when we look from the point of virtual teams, the importance of learning among virtual teams in which an unsynchronized communication exists and the team members are at different locations is becoming clearer.

In this study, the relation between the team learning and team performance is analyzed theoretically and empirically in terms of virtual teams. In this framework, as a result of evaluating the hypothesis with the data 
collected over the virtual teams, it is being expected that important contributions about the teams will be done to the related literature. In the following chapter, virtual team concepts, learning with leadership in virtual teams are being underlined and related hypotheses have been developed. In the methodology part, the related hypotheses were tested with the statistical analysis programs and in the last part findings have been discussed and interpreted.

\section{Literature Review}

\subsection{Virtual Teams}

Although working teams were created in the 1960s in America, widespread use of the term "team" was began in 1980s with Total Quality Management acts. In the late 1980s and in the early 1990s, self management/fortified team concepts and practices have become widespread. In the middle of 90 s, leading companies as Goodyear, Motorola and General Electric started to develop global human resources practices by creating a team with their employees working in different locations (Kirkman et al., 2002). With ongoing globalization and communication technologies, virtual teams have become popular and practicable anywhere in the world (Walvoord et al., 2008).

Before defining virtual teams, it will be beneficial to explain what the team is; to talk about a team, all members must be in communication with each other and they must work for common goals (Cascio \& Shurygailo, 2003, p. 362 ). Team can be defined as: it is a social group perceived as a team by its members and environment consisting of people who come together to realize a common goal (Senior \& Swailes, 2004, p. 318). The most important difference between virtual teams and teams having physical interaction is the distance in time and extent between team members (Cascio \& Shurygailo, 2003, p. 362).

We can divide teams according to interaction between its members (Cascio \& Shurygailo, 2003, p. 362):

1. Physical interactive teams: as sport teams, orchestras or aircrew.

2. Non-physical interactive teams: as virtual teams or project groups.

In the membership of physical teams, people are in communication with each others about business and non-business issues. Information sharing is at minimal levels in virtual teams. Physical teams have more changes on the subject of resource sharing and allocation. In physical teams, director has an environment to define and control the requirements and necessities. But in virtual teams, for the director; it's limited to control and notice the error and intervene. Similarity level of culture and education is better in physical teams (Staples \& Zhao, 2006). Virtual teams have more technological activities than physical teams.

In the Table 1, differences between traditional teams and virtual teams are summarized. 3 factors used to explain differences between them, of course are influenced with each other. For example, if team members are working in different locations from each other, it wouldn't be practical to rely using face to face communication mode, and it would be impossible to apply (Kratzer et al., 2004, p. 2).

Table 1. Comparison of traditional teams and virtual teams (Kratz et al., 2004, p. 2)

\begin{tabular}{ll}
\hline Traditional teams & Virtual teams. \\
\hline Team members are on same location & All team members are on different locations from each others \\
Team members are on face to face communication & Team members have asynchronous communication \\
There is synchronous communication & Tasks are very structured and certain, and it is rarely required to \\
Team members coordinate the task in a mutual reconciling & coordinate team members \\
\hline
\end{tabular}

Examining relevant literature, it is clearly seen that there is no consensus about the definition of virtual team. Actually the concept virtual represents multiple corporate connections (Choduba et al., 2005). But team can be defined as a group of people having mutual responsibility for a purpose and complementary qualifications (Zenun et al., 2007). But according to Anderson (2007, p. 2559) virtual team is a definition which has widespread activities and it concludes technology-oriented works. That is, team members working in more than a physical location, using computer oriented communication, sharing individual efforts and inputs by technology (Peters et al., 2007, p. 118).

Benefiting from DeSanctis and Monge (1999) and Jarvenpaa and Leidner (1999); virtual team can be defined as: These are temporary teams whose team members are in communication in technological environment and 
working in different geographical areas. Although virtual teams may take several forms according to team membership, researches made in past shows us that virtual teams are formed often with the experts from different organizations or different units from the same organizations (Yoo \& Alavi, 2004, p. 28).

Townsead and his colleagues (1998, p. 17) defines virtual team as: It's a group consisting of geographically and/or organizationally dispersed employees coming together by using communication and information technologies combination with the aim of making an organizational job/task (Bell \& Kozlowski, 2002, p. 3). Companies can create virtual teams for many reasons. The most important reason of this is to save office areas, especially for people who pass a small part of his time in office as salespeople or consultants. Thus, such employees will be able to spend more time with their customers. Virtual teams generally are created to cope with the differences of location and time (Cascio \& Shurygailo, 2003, p. 362). However, it is not easy to cope with these differences and to create working team regularly working by the same time. At this point, leadership comes along.

\subsection{Leadership in Virtual Teams}

Leader represents gathering a group of people around certain purposes, and total knowledge and skills deploying them to accomplish these goals. Directing a group of people coming together because of a specific goal that requires a separate skill and persuasive ability (Eren, 2003, p. 525).

Changing conditions make amendments in the form of leadership according to environment. Social and scientific developments cause the emergence of many theories and application forms on the subject of leadership and enrich the written literature about leadership (Eren, 2003, p. 525).

Leadership is one of the most significant problems of virtual teams. Coordination requirements, resource constraints, measurability of improvement and approximation of assignment limits and of team limits are important issues that a leader has to deal (Cascio \& Shurygailo, 2003, p. 366). All kinds of direct control get difficult for team leader especially because the members of a virtual team and the team leader are on different locations. Thus, Tayloristic principles (such as; electronic performance monitoring) are inconvenient for virtual teams, delegation of authority principles are preferred instead, for example the transfer of leadership functions to the team members (Hertel et al., 2005, p. 80-82).

Culture has a great impact on virtual leaders. In virtual teams, the culture of the company is superior to national culture. National cultures may be individual or collectivist. There have been many researches on individual cultures however $70 \%$ of the world population, at least, has collectivist culture. The virtual leader is to be sensitive to national cultural norms, which is especially very significant for multinational teams namely the virtual teams spreading to different locations throughout the world (Cascio \& Shurygailo, 2003, p. 374). However it is really hard to describe a specific leadership convenient for virtual teams. Hence it is expected from leaders to analyze the coherency and relation between the virtual working environment and their leadership styles and to act in accordance with the situation (Cascio \& Shurygailo, 2003, p. 362-363).

The working environment of virtual teams is a virtual place created by means of information and telecommunication technologies. This is the key factor which distinguishes the virtual team leadership from team leadership. Information Technologies is not only predominant fact for accomplishing the communication between the virtual team leader and the members, but also for accomplishing organizational tasks and their spread. The more visual the virtual interactions gets, the more parallel the virtual leadership becomes with conventional leadership in terms of content and style (Avolio \& Kahai, 2003, p. 327). When viewed from this aspect, it is possible to use the leadership styles in traditional literature for the surveys of virtual leadership. In this point it is thought that the task, relationship and change oriented leadership styles of Yukl (1998) are adoptable for virtual teams in terms of being used for teams and being parallel with the reflexive and administrative leadership styles which are wide spread taxonomies in literature.

The detailed information about the leadership styles is set out below.

1) Task-oriented leadership: The leader focuses on the organization of job activities within the context of task focus leadership. The leaders behaving task-oriented define the milestones of the projects, the needs for resources, the roles that team members play and their performance standards and set off an action plan. Moreover, task-oriented leadership style includes facilitating information acquisition and sharing, developing solutions for the problems of team fast. As considered from this point of view, the task oriented leadership style embodies the elements parallel with executive leadership style (Strang, 2004). 
2) Relationship-oriented leadership: The leaders behaving relationship-oriented concern about the team members, pay attention to their worries and encourage them. In addition to these, the relationship-oriented leaders ask the team members' opinion and suggestion about the decisions which affect the team members. The relationship oriented leathers are described namely as the life coaches who guide the team members for their individual attitudes and behaviors and their professional lives (Strang, 2004).

3) Change-oriented leadership: The leaders behaving change-oriented lead by means of examples and they set an example with their behaviors. They are role models. They motivate the team by expressing his trust in the team on every occasion to achieve their goals. The leaders develop strategies with regard to organization's vision for the team and authorize the team members to apply the new strategies. Change-oriented leaders try new approaches, pursue new opportunities, convince the team members about the changes and guide them to practice the changes. In addition to this, the change-oriented leaders encourage the team members to learn and contribute to team learning. When considered from this point of view, change oriented leadership, in itself, shows a parallel approach with transformational leadership style (Strang, 2004).

\subsection{Team Learning}

When the related literature is analyzed, it is seen that there are many issues about the creation, structure and success of teams to be clarified (Ancona, 1990, p. 334). One of them, maybe the most important issue, closely related to how the teams solve the vague and complicated problems is to be discussed under the title of 'team learning'. Team level learning consists of vision shared among team members, mental models and communication and it is described as the process of responding with the unexpected problems rather dealing with the improvement of the teams (Kayes, 2003). As a matter of fact, when the new problems occurs in today's rapidly changing, competitive and vague conditions, finding out the affective factors in team learning process is of vital importance, since very few team has the luxury for dealing with the time consuming process (Maani $\&$ Benton, 1999; Akgün et al., 2002).

According to Avery (2000), Coghlan (2001), Delbridge et al. (2000), Fisher and Fisher (1998), Goh (1998) the principle of team working is based on the faith of the team members that they will bring their knowledge, skills and experiences to the team. The teams are the keys structures in the organizations where learning realizes. (Nonaka \& Takeuchi, 1995; Senge, 1990). Teams consist of individuals from different professions and come up against the various problems today's changing world. At this point, the team members' knowledge and experiences is not enough, different teams, consultancies, clients, suppliers, universities, expos, institutions like KOSGEB or TUBITAK constitute knowledge source for the teams. From this point of there are two kinds of team learning. 1) Internal team learning means the team members bring knowledge, skills and experience to the workplace and attribute them to the team level; 2) External team learning means outsourcing to solve the problems encountered by team (Edmondson \& Nembhard, 2009).

With the intention of keeping up with the rapidly changing market conditions, the teams, no matter they are traditional or virtual, are given more responsibilities and autonomies. Besides the teams consisting of members from different professions are becoming widespread. It is said that team learning has more important role than the competitiveness of the organizations (Chan et al., 2003, p. 175). However, to be able to perform the role, the phenomenon of leadership gets on the stage. Virtual teams consist of geographically dispersed members who coordinate the organizational tasks by information and telecommunication technologies (i.e., e-mail, video conferencing). The rapid development of innovative communication technologies expedites the tendency towards virtual teams (Hertel et al., 2005, p. 69-70). It is expected that leadership has a positive impact on performing team learning especially in virtual teams in which the communication and coordination is very complicated. Therefore:

H1: Leadership in virtual teams a) task-oriented leadership, b) relationship-oriented leadership, c) change-oriented leadership has a positive impact on internal team learning.

H2: Leadership in virtual teams a) task-oriented leadership, b) relationship-oriented leadership, c) change-oriented leadership has a positive impact on external team learning.

Team-oriented problem solving and learning are the fundamental characteristics of virtual teams (Tran \& Latapie, 2007 , p. 27). Although there are many surveys on the relationship between team learning and organizational competitiveness, the surveys on team learning and team performance are less comparatively. Chan et al. (2003, p. 179) studied on a research made in a hospital in Australia with the 189 employees from different departments to analyze the effects of internal \& external team learning on team performance. A research on surgical team in 16 
large scaled medical centre by Edmondson and his colleagues (2001) shows that there is a positive relationship between the adaptation skill of team to new working methods and team performance. Another study by Edmondson (1999) on 51 teams in a manufacturing company shows the indirect relationship between team learning behaviors, team performance and team psychological confidence. A research by Cavaluzzo (1996), Flood and his colleagues (2001), Katzenbach and Smith (1993), Meyer (1994), Roberts (1997) and Senge (1992) clearly shows that the team learning affects team performance positively. These studies show how important the learning is in terms of team performance (Chan et al., 2003, p. 175). Therefore:

H3: Internal team learning in virtual teams has positive effect on team performance.

H4: External team learning in virtual teams has positive effect on team performance.

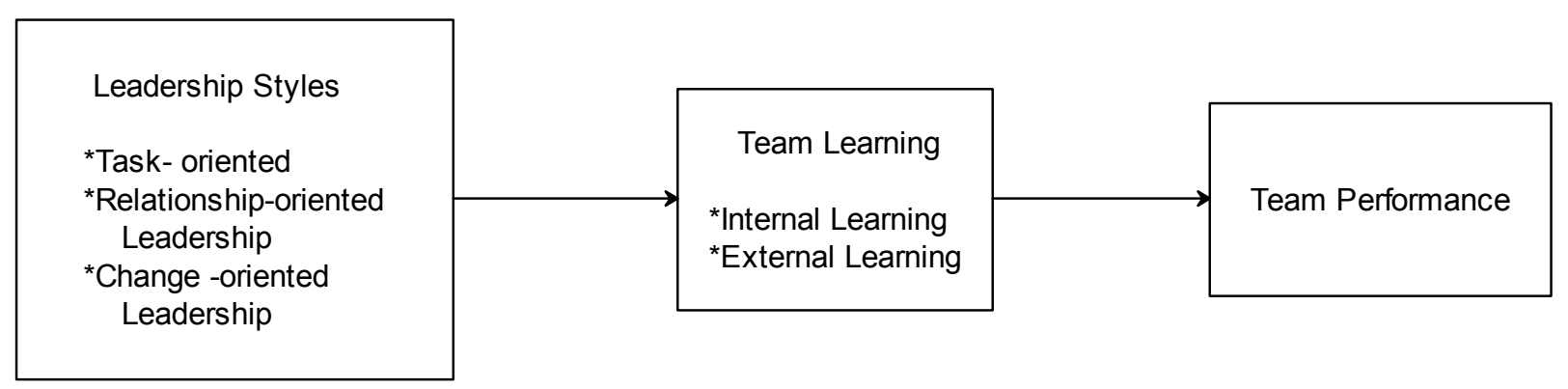

Figure 1. Research model

\section{Methodology}

\subsection{Scales}

With the purpose of examining the hypotheses the questionnaires which are enhanced from former studies and adopted, are used. The concepts are measured by 5 point likert scale; "from 1: strongly disagree to 5: strongly agree". However Project team size as a control variable is evaluated with ratio scale. The survey questions are in the factor analysis table. There is brief summary of scales below.

\subsubsection{Leadership}

To measure leadership in virtual teams Yukl's (1998) Leadership Behavioral Taxonomies can be referred. Leadership Behavioral Taxonomies is a classification to analyze the characteristics and behaviors of leaders. It was published in 1981, then, updated by Yukl in 1998. This taxonomy is based upon the former studies and models and measured with the leadership behavior scale consisting of 22 items, excerpted from Strang (2004).

1) Team Learning: To measure team learning in virtual teams, team learning scale consisting of 9 items taken from Chan vd's studies (2003) is used.

2) Team Performance: To measure team performance in virtual teams, team performance scale consisting of 4 items taken from the studies of Greiner (2004), Chan et al. (2003) and Erdem, Ozen and Atsan (2003) is used.

\subsection{Sampling}

After determining the scales that would be used, the questions are reviewed after the discussion with the academicians in Turkey specialized in questionnaire draft, organizational behavior and innovation. The coherence of the questionnaire with Turkish version is tested by means of parallel translation method, which means the questions are translated into Turkish and the translated questions in Turkish translated in English and in the end these questions are compared with the originals. As a result of this comparison the coherence between the source and translated text is approved. It is tested in advance with 5 master degree students working in industry and experienced a virtual team position at least once to test the coherence of the Turkish text. The final shape is given. After this, with the personally applied questionnaire method, questionnaire is delivered to related persons and handled. The questions are attached.

Sampling of the research comprise of virtual teams of 80 firms, which has its head quarter in İstanbul, use information technologies mostly, has branches at least three different locations abroad or in the country. In 
addition to this, these firms adopt the western style management and organizational approaches. For example they are compatible ISO standards and European Quality Standards. Firstly the general managers, owners or the authorized people are informed about the aim of the study via phone, e-mail or by visiting the ones who are in İstanbul. 53 out of 80 firms accept the study. It is asked that only one participant join the study in each virtual team. After participants are determined, each participant is informed that their answer will be evaluated without using their names and their answers are not correlated with the products the participants create. Informing the participants that the questionnaire will be anonymous, it increases their motivation of cooperation without restoration. In addition to this, it is highlighted that there is no true or false answer and the participants are asked to be as honest and clear as they could be when they answer the questions. Besides this, a story is developed to show that the independent variable and measured variable are not related. These procedures decrease the worries of individuals and the tendencies to answer the questions responsively with society, temperately or the way they think the question writers would like (Podsakoff et al., 2003).

There are 101 survey (including the firms participating with more than one virtual team) after the 35 out of 53 firm who accept the answering the questions. Therefore, the sampling to be analyzed is determined 35 firms and 101 by means of some firms participating with more than one questionnaire. The characteristics of the sampling are given on table 2 below.

Table 2. The characteristics of the sample

\begin{tabular}{|c|c|c|}
\hline & Frequency & $\%$ \\
\hline \multicolumn{3}{|l|}{ Industry } \\
\hline Manufacturing & 21 & 20.79 \\
\hline Information \&Communication Technology & 57 & 56.43 \\
\hline Financial services & 23 & 22.77 \\
\hline Total & 101 & 100 \\
\hline \multicolumn{3}{|l|}{ Duration of projects (months) } \\
\hline Less than 3 months & 14 & 13.86 \\
\hline $4-6$ & 43 & 42.57 \\
\hline 7-9 & 29 & 28.71 \\
\hline $10-18$ & 12 & 11.88 \\
\hline Over 18 months & 3 & 2.97 \\
\hline Total & 101 & 100 \\
\hline \multicolumn{3}{|l|}{ Respondent position } \\
\hline Senior engineer/ Technical leader & 17 & 16.83 \\
\hline Department manager & 11 & 10.89 \\
\hline Product/project manger & 23 & 22.77 \\
\hline Engineer/ Programmer & 37 & 36.63 \\
\hline IS specialist/analyst & 13 & 12.87 \\
\hline Total & 101 & 100 \\
\hline
\end{tabular}

\subsection{Analysis and Results}

Partial Least Squares (PLS-Graph 3.0, Chin, 2001) approach is used to measure the scales inclusive of Structural Equation Modelling (SEM) and structural parameters.

\subsection{Measurement Validity and Reliability}

In parallel with Kleijnen, Ruyter and Wetzels's (2007) studies, the reflective measurement model is used for all variables in this study. To evaluate psychometric properties of measurement tools a null model is used. Composite Reliability (CR) and Average Variance Extracted (AVE) are used for measurement of reliability. It seen for all measurements is above the threshold value 0.70 of PLS based CR value and AVE value exceed the 
threshold value 0.50 . In addition to this the convergent validity is tested by means of calculating the standardized loading of the measurements on the concepts and it is found that all measurements display standardized loading exceeding 0.60 (see Table 3). Following this, the differentiation validity of measurements is tested. As Fornell and Larcker (1981) states AVE value measured for each variable is higher than the hidden factor correlations (see Table 4). It shows that the measurement meets the validity and reliability criteria.

Table 3. Factor analysis of measurements, CR and AVE values

\begin{tabular}{|c|c|c|c|}
\hline & Factor scores & $\mathrm{CR}$ & AVE \\
\hline Task oriented leadership & & .927 & .628 \\
\hline Determines what resources are needed to do a project. & .81 & & \\
\hline Clarifies role expectations for project members & .80 & & \\
\hline Clarifies quality standards for task performance.. & .84 & & \\
\hline Facilitates collection and dissemination of information. & .83 & & \\
\hline Actively monitors operations and performance. & .83 & & \\
\hline Resolves immediate questions or problems from team & .80 & & \\
\hline Relationship oriented leadership & & .921 & .661 \\
\hline Actively provides support and encouragement. & .81 & & \\
\hline Socializes with team beyond work to build relationships. & .83 & & \\
\hline Publicly recognizes contributions and accomplishments. & .87 & & \\
\hline Provides individual role and/or behavior coaching. & .82 & & \\
\hline Consults with members on decisions affecting them. & .75 & & \\
\hline Helps team members (as a group) resolve conflicts. & .77 & & \\
\hline Change Orientation leadership & & .945 & 632 \\
\hline Creates sense of urgency, promotes change. & .78 & & \\
\hline Studies other projects to get ideas for improvements. & .79 & & \\
\hline Envisions exciting new possibilities for the organization. & .78 & & \\
\hline Develops strategies linked to organization_s vision. & .79 & & \\
\hline Builds coalition of stakeholders to get change approved. & .81 & & \\
\hline Creates task force to guide implementation of change & .81 & & \\
\hline Suggests symbolic changes that affect the work. & .84 & & \\
\hline Empowers members to implement new strategies. & .82 & & \\
\hline Announces, celebrates progress supporting changes. & .75 & & \\
\hline Encourages/facilitates learning by team members & .70 & & \\
\hline Internal Team Learning & & .884 & .604 \\
\hline In our group, people discuss ways to prevent and learn from mistakes & .77 & & \\
\hline We regularly take time to figure out ways to improve our work processes & .79 & & \\
\hline $\begin{array}{l}\text { Problems and errors in our group are never communicated to the appropriate people so that } \\
\text { corrective action can be taken }\end{array}$ & .78 & & \\
\hline In my group, someone always makes sure that we stop to reflect on our work process & .80 & & \\
\hline People in my group often speak up to test assumptions about issues under discussion & .73 & & \\
\hline External Team Learning & & .871 & .628 \\
\hline My group frequently coordinates with other groups to meet organizational objectives & .76 & & \\
\hline My group keeps others in the organization informed about what we plan and accomplish & .85 & & \\
\hline
\end{tabular}


Group members go out and get all the relevant work information they possibly can from $\quad .80$

others - such as customers, or other parts of the organization

We invite people from outside the group to present information or have discussion with us 73

Team Performance

Others seldom complain about my group's work

Team members solve problems quickly

The quality of the work done by this team develops continuously

\section{Findings}

We used PLS path modeling which allows for explicit estimation of latent variable (LV) scores, to estimate the main effects in our model (see Figure 1). We used PLS Graph 3.0 and Bootstrapping resampling method to test their statistical significance. This procedure entailed generating 500 sub-samples of cases randomly selected, with replacement, from the original data. Path coefficients were then generated for each randomly selected subsample. $T$-statistics were calculated for all coefficients, based on their stability across the subsamples, indicating which links were statistically significant.

As shown in Table 5, the results illustrate that our hypotheses are largely confirmed. For the relationship between leadership behaviors and internal learning; task-oriented leadership $(\beta=.28, p<.01)$ and relationship oriented leadership $(\beta=.16, p<.01)$ are found to have positive relationship with internal learning in virtual teams and partially confirms $\mathrm{H} 1$. The findings for external learning, task-oriented leadership $(\beta=.13, p<.05)$ and change-oriented leadership $(\beta=.21, p<.01)$ it is seen that it has positive relationship with external learning in virtual teams and partially confirms $\mathrm{H} 2$. In addition to this, the results of the analysis prove that there is a positive relationship between internal learning and team performances $(\beta=.23, p<.05)$ and external learning and team performances $(\beta=.18, p<.1)$ and confirm H3 and H4. Surprisingly according to the findings there is no statistical relationship between change oriented leadership and internal learning, relationship-oriented leadership and external learning.

Finally according to the results seen on Table 5, leadership behaviors explains the $23 \%$ of changes on internal learning in virtual teams and $16 \%$ of changes on external learning in virtual teams. The model displays the $25 \%$ changes on team performances $\left(\mathrm{R}^{2}=.25\right)$.

Table 5. Path analysis results

\begin{tabular}{llll}
\hline Hypothesis & Relations & $\beta$ & Results \\
\hline H1 & Task-oriented Leadership $\rightarrow$ Internal Learning & $.28^{* *}$ & Partial \\
& Relationship-oriented Leadership $\rightarrow$ Internal Learning & $.16^{* *}$ & Confirmed \\
& Change-oriented Leadership $\rightarrow$ Internal Learning & .07 & Partial \\
& Task-oriented Leadership $\rightarrow$ External Learning & $.13^{*}$ & Confirmed \\
H2 & Relationship-oriented Leadership $\rightarrow$ External Learning & .09 & Confirmed \\
& Change-oriented Leadership $\rightarrow$ External Learning & $.21^{* *}$ & Confirmed \\
H3 & Internal Learning $\rightarrow$ Team Performance & $.31^{* *}$ & $.25^{* *}$ \\
\hline Consistency Scales & External Learning $\rightarrow$ Team Performance & & Ultimate Model \\
\hline$R^{2}$ & Endogenous Variables & & .23 \\
& Internal Learning & & .16 \\
\hline
\end{tabular}

Note. ${ }^{*} p<.05 ;{ }^{* *} p<.01$ 


\section{Discussion and Conclusion}

Virtual Teams catch the attention of researchers from different disciplines and the executives from business world by means of increasingly wide spreading application and increasing popularity in literature. Despite the increasing popularity of virtual teams, it is seen that the empirical studies on virtual teams are not sufficient. Especially the gap concerning the success and performance determiner in virtual teams, differing from conventional teams in terms of time and place, has not been filled yet. This paper aims to unveil the mystery on success and performance determiner in virtual teams. For this purpose the concept of virtual team is analyzed by means of literature review and it is understood that there are many problems with management and leadership in virtual teams. In addition to this team learning in virtual teams is also vital for team success. Hence, it is aimed in this study that in the context of virtual teams the relationship among leadership behaviors, team learning and team performances evaluated holistically and aim to contribute the management literature.

According to the research results, it is seen that leadership, team learning and team effectiveness scales developed in Western countries and applied for the conventional teams keep the validity and reliability for virtual teams and Turkey which is a developing country and. In this paper the relationship between leadership behaviors and team learning in virtual teams is also analyzed. The findings reveal the direct and strong relationship between task-oriented and relationship-oriented leadership and internal learning; task-oriented and change-oriented leadership and external learning.

This findings shows that in virtual teams when leaders determine the roles of team members, their performance standards, business activities, plans and interest in the team members one to one and mentor them rather being a formal director, the team members will have tendency to share their individual level knowledge, skills and specialties. Therefore the intangible values shared go from individual level to team level and contribute the internal learning. Besides this, the findings when the leaders in virtual teams produce business plans and standardize the performance evaluation, team activities and the role of members and add datum about change and innovation to these standards and plans, it is seen that teams get more successful to create new solutions to solve the problems encountered by means of external sources and to obtain new skills. To sum up these findings; the task-oriented leadership, meaning that the leaders determine the standards for business plans, is a sin aqua non for both internal and external learning. In addition to this, to realize the internal learning, the leaders are to interest in team members one to one and encourage them to share knowledge and reliability and to realize the external learning, the leaders are to be open to changes and express that change is a must and determine business plans and standards accordingly.

Last but not least this study aims to contribute the related literature by means of analyzing the relationship between team learning and team performances in the concept of virtual teams. The findings provide in support of the strong relationship between both internal and external learning and team performance. These results, similar to the extant literature, underlines the fact that as the usage of teams becomes a structural norm, team problem solving in terms of team learning is a perquisite for team performance and success (e.g., Reus \& Liu, 2004, p. 245; Green et al., 2005, p. 350). In other words, no matter in virtual or traditional team-the most important determiners of teams' success and performance is offering a solution for the problems encountered, namely realizing a team level learning.

There are some limitations to this study that constraint the generalizability of the results. First of all the results should be considered that the study conducted in a developing country, Turkey and the truth that the results may change in societies from different cultural and economic backgrounds cannot be slighted. Besides it is seen that there is a need for another study for traditional teams since this paper deals with the virtual teams. Moreover, this paper's findings focus on the datum taken from 101 team members. The more crowded participants provide the results with higher generalization level. This paper is important however it only deals with the success and performance in virtual teams, which is still mysterious concept. From this point, it is obvious that the concept of virtual teams constitutes a rich research are for further analysis. It is highly advised further researchers to include the new variables like psychological safety and climate when they analyze team learning and performance in virtual teams, to increase the number of people in sampling and to use the primary data (such as datum of the company) rather attitude scales to evaluate the team performance.

\section{References}

Akgun, A. E., Lynn, G. S., \& Reilly, R. (2002). Multi-dimensionality of learning in new product development teams. European Journal of Innovation Management, 5(2), 57-72. http://dx.doi.org/10.1108/14601060210428168

Ancona, D. G. (1990). Outward bound: strategies for team survival in the organization. Academy of Management 
Journal, 33(2), 334-365. http://dx.doi.org/10.2307/256328

Anderson, A. H., Mcewan, R., Bal, J., \& Carletta, J. (2007). Virtual team meetings: An analysis of communication and context. Computers in Human Behavior, 23, 2558-2580. http://dx.doi.org/10.1016/j.chb.2007.01.001

Avery, C. M. (2000). How teamwork can be developed as an individual skill. Journal of Quality \& Participation, 23(4), 6-13.

Avolio, B. J., \& Kahai, S. S. (2003). Adding the 'E' to E-Leadership: How It may Impact Your Leadership. Organizational Dynamics, 31(4), 325-338. http://dx.doi.org/10.1016/S0090-2616(02)00133-X

Badrinarayanan, V., \& Arnett, D. B. (2008). Effective virtual new product development teams: an integrated framework. Journal of Business and Industrial Marketing, 23, 242-248. http://dx.doi.org/10.1108/08858620810865816

Bell, B. S., \& Kozlowski, S. W. J. (2002). A topology of virtual teams: Implications for effective leadership. Group and Organization Management, 27(1), 14-49. http://dx.doi.org/10.1177/1059601102027001003

Cascio, W. F., \& Shurygailo, S. (2003). E-Leadership and Virtual Teams. Organizational Dynamics, 31(4), 362-376. http://dx.doi.org/10.1016/S0090-2616(02)00130-4

Cavaluzzo, L. (1996). Enhancing team performance. The Healthcare Forum Journal, 39(5), 57-69.

Chan, C. A., Pearson, C., \& Entrekin, L. (2003). Examining the Effects of Internal and External Team Learning on Team Performance. Team Performance Management: An International Journal, 9(7/8), 174-181. http://dx.doi.org/10.1108/13527590310507426

Chin, W. (2001). Pls-graph user's guide version 3.0. Houston, Tx: C.T. Bauer College of Business, University of Houston.

Chudoba, K. M., Wynn, E., Lu, M., \& Watson-Manheim, M. B. (2005). How virtual are we? Measuring virtuality and understanding its impact on a global organization. Information Systems Journal, 15, 279-306. http://dx.doi.org/10.1111/j.1365-2575.2005.00200.x

Coghlan, D. (2001). Insider aciton research projects: implications for practicing managers. Management Learning, 32(1), 49-60. http://dx.doi.org/10.1177/1350507601321004

Delbridge, R., Lowe, J., \& Oliver, N. (2000). Shopfloor responsibilities and under lean teamworking. Human Relations, 53(11), 1459-1479.

Desanctis, G., \& Monge, P. (1999). Introduction to the special issue: communication processes for virtual organizations. Organizational Science, 10(6), 693-703. http://dx.doi.org/10.1287/orsc.10.6.693

Ebrahim, N. A., Ahmed, S., \& Taha, Z. (2009). Virtual Teams: a Literature Review. Australian Journal of Basic and Applied Sciences, 3(3), 2653-2669.

Edmondson, A. (1999). Psychological safety and learning behavior in work teams. Administrative Science Quarterly, 44, 350-383. http://dx.doi.org/10.2307/2666999

Edmondson, A., Bohmer, R., \& Pisano, G. (2001). Speeding up team learning. Harvard Business Review, October, $125-132$.

Edmondson, A. C. (1996). Group and organizational influences on team learning. Unpublished doctoral dissertaion, Harvard University, Boston, MA.

Edmondson, A. C., \& Nembhard, I. M. (2009). Product development and learning in project teams: the challenges are the benefits! J. Prod. Innov. Manag, 26, 123-138. http://dx.doi.org/10.1111/j.1540-5885.2009.00341.x

El-Tayeh, A., Gil, N., \& Freeman, J. (2008). A methodology to evaluate the usability of digital socialization in "virtual" engineering design. Research in Engineering Design, 19, 29-45. http://dx.doi.org/10.1007/s00163-007-0037-7

Eren, E. (2003). Yönetim ve Organizasyon (Çağdaş ve Küresel Yaklaşımlar). Beta Basım A. Ş., 6. Baskı.

Fisher, K., \& Fisher, M. D. (1998). Shedding light on knowledge work learning. Journal for Quality \& Participation, 21(4), 8-16.

Flood, P., Maccurtain, S., \& West, M. (2001). Effective Top Management Teams: An International Perspective. Dublin: Balckhall Publishing. 
Goh, S. C. (1998). Toward a learning organization: the strategic building blocks. S.A.M. Advanced Management Journal, 63(2), 15-22.

Green, A. L., Hill, A. Y., Friday, E., \& Ve Friday, S. S. (2005). The use of multiple intelligences to enhance team productivity. Management Decision, 43(3), 349-359. http://dx.doi.org/10.1108/00251740510589742

Hertel, G., Geister, S., \& Konradt, U. (2005). Managing Virtual Teams: A Review of Current Empirical Research. Human Resource Management Review, 15(1), 69-95. http://dx.doi.org/10.1016/j.hrmr.2005.01.002

Jarvenpaa, S. L., \& Leidner, D. E. (1999). Communication and trust in global virtual team. Organization Science, 10(6), 791-865. http://dx.doi.org/10.1287/orsc.10.6.791

Joseph, B. L., \& Tamera, R. S. (2005). The influence of emotional intelligence on performance. Personality and Individual Differences Volume, 39(4), 693-703. http://dx.doi.org/10.1016/j.paid.2005.02.018

Katzenbach, J. R., \& Smith, D. K. (1993). The discipline teams. Harvard Business Review, March-April, $111-120$.

Kayes, C. D. (2003). Proximal team learning: Lessons from United Flight 93 on 9/11. Organizational Dynamics, 32(1), 80-92. http://dx.doi.org/10.1016/S0090-2616(02)00139-0

Kirkman, B. L., Rosen, B., Gibson, C. B., Tesluk, P. E., \& Mcpherson, S. O. (2002). Five challenges to virtual team success: Lessons from Sabre, Inc. Academy of Management Executive, 16(3), 67-79. http://dx.doi.org/10.5465/AME.2002.8540322

Kleijnen, M., Ruyter, K. D., \& Wetzels, M. (2007). An assessment of value creation in mobile service delivery and the moderating role of time consciousness. Journal of Retailing, 83(1), 33-46. http://dx.doi.org/10.1016/j.jretai.2006.10.004

Kratzer, J., Leenders, R. Th. A. J., \& Van Engelen, Jo. M. L. (2004). Managing creative team performance in virtual environments: an empirical study in $44 \mathrm{R} \& \mathrm{D}$ teams. Technovation, 1-8.

Krishna, P., \& Akhilesh, K. B. (2002). Global virtual teams: what impacts their design and performance? Team Performance Management, 8(5/6), 102-112. http://dx.doi.org/10.1108/13527590210442212

Maani, K., \& Benton, C. (1999). Rapid team learning: lessons from team New Zealand America's cup campaign. Organizational Dynamics, 28(4), 48-72. http://dx.doi.org/10.1016/S0090-2616(99)90029-3

Meyer, M. A. (1994). The dynamics of learning with team production implications for task assignment. Quarterly Journal of Economics, 109(4), 1157-1184. http://dx.doi.org/10.2307/2118359

Munkvold, B. E., \& Zigurs, I., (2007). Process and technology challenges in swift-s tarting virtual teams. Information and Management, 44, 287-299. http://dx.doi.org/10.1016/j.im.2007.01.002

Peters, L. M., \& Manz, C. C. (2007). Identifying antecedents of virtual team collaboration. Team Performance Management, 13, 117-129. http://dx.doi.org/10.1108/13527590710759865

Podsakoff, P. M., Mackenzie, S. B., Lee, J. Y., \& Podsakoff, N. P. (2003). Common method bias in behavioral research: a critical review of the literature and recommended remedies. Journal Applied Psychology, 88, 879-903. http://dx.doi.org/10.1037/0021-9010.88.5.879

Reus, T. H., \& Liu, Y. (2004). Rhyme and reason: emotional capability and the performance of knowledge-intensive work groups. Human Performance, 17, 245-266. http://dx.doi.org/10.1207/s15327043hup1702_6

Roberts, E. (1997). When is enough ... enough? Journal for Quality \& Participation, 39(5), 16-20.

Senge, P. M. (1992). The Fifth Discipline: The Art \& Practice of the Learning Organization. Australia, Milson Point, New South Wales: Random House.

Senior, B., \& Swailes, S. (2004). Dimensions of the Management Team Performance: A Repertory Grid Study. International Journal of Productivity and Performance Management, 53(4), 317-333. http://dx.doi.org/10.1108/17410400410533908

Staples, D. S., \& Zhao, L. (2006). The Effects of Cultural Diversity in Virtual Te ams Versus Face-to-Face Teams. Group Decision and Negotiation, 15, 389-406. http://dx.doi.org/10.1007/s10726-006-9042-x

Townsend, A. M., Demarie, S. M., \& Hendrickson, A. R. (1998). Virtual teams: Technology and the workplace of the future. Academy of Management Executive, 12, 17-29.

Tran, V. N., \& Latapie, H. M. (2007, Summer). Developing Virtual Team Problem-Solving and Learning 
Capability using the Case Method. The Business Review, 8(1).

Walvoord, A. A. G., Redden, E. R., Elliott, L. R., \& Coovert, M. D. (2008). Empowering followers in virtual teams: Guiding principles from theory and practice. Computers in Human Behavior (article in press). http://dx.doi.org/10.1016/j.chb.2008.02.006

Yoo, Y. J., \& Alavi, M. (2004). Emergent Leadership in Virtual Teams: What Do Emergent Leaders Do? Information and Organization, 14, 27-58. http://dx.doi.org/10.1016/j.infoandorg.2003.11.001

Zenun, M. M. N., Loureiro, G., \& Araujo, C. S. (2007). The Effects of Teams' Co-location on Project Performance. In Loureiro, G., \& Curran, R. (Eds.). Complex Systems Concurrent Engineering-Collaboration, Technology Innovation and Sustainability. London: Springer. http://dx.doi.org/10.1007/978-1-84628-976-7_79

\section{Copyrights}

Copyright for this article is retained by the author(s), with first publication rights granted to the journal.

This is an open-access article distributed under the terms and conditions of the Creative Commons Attribution license (http://creativecommons.org/licenses/by/3.0/). 